\title{
Forecasting $\mathrm{N}_{2} \mathrm{O}$ emission and nitrogen loss from swine manure composting based on BP neural network
}

\author{
Haotian Chen, Shaoze Sun, and Baoli Zhang* \\ College of Resources and Environmental Sciences, China Agricultural University, Beijing 100193, \\ China
}

\begin{abstract}
Nitrogen loss and greenhouse gas emission during compost will cause secondary pollution and waste nutrients. To address this issue, a predictive model was set up to obtain a clear knowledge of the $\mathrm{N}_{2} \mathrm{O}$ emission and nitrogen loss from swine manure composting. This paper collected 68 group data from 11 published papers about pig manure composting $\mathrm{N}_{2} \mathrm{O}$ emission and total nitrogen loss. Select 4 indexes were taken as predicted indexes include aeration rate, moisture content, $\mathrm{C} / \mathrm{N}$, and the amount of superphosphate to establish a BP neural network for forecasting the $\mathrm{N}_{2} \mathrm{O}$ emission and total nitrogen loss from composting. The analyses show that the mean error of $\mathrm{N}_{2} \mathrm{O}$ emission forecasting model is 1.17 ; the value of MAPE is $138.85 \%$. As for nitrogen loss, the mean error is 24.72 and the mean absolute percentage error is $11.06 \%$. Compare to the traditional linear regression, the BP neural network model has good accuracy on forecasting $\mathrm{N}_{2} \mathrm{O}$ emission and TN loss from manure composting. BP neural network has considerable application prospect in forecast nitrogen loss and greenhouse gas emission from composting.
\end{abstract}

\section{Introduction}

Composting is an effective way to reuse nutrients in livestock manure. However, $\mathrm{N}_{2} \mathrm{O}$ emission from composting will cause secondary environmental pollution and also waste nitrogen in the manure. It was reported that $0.2-9.9 \%$ of initial total $\mathrm{N}$ is lost as $\mathrm{N}_{2} \mathrm{O}$ from nitrification or denitrification [1-3]. Several studies have concluded that add superphosphate will fix nitrogen and reduce $\mathrm{N}_{2} \mathrm{O}$ emission from manure composting [4-6]. Besides, other parameters during composting like $\mathrm{C} / \mathrm{N}$ ratio, aeration rate and moisture content also have effect on $\mathrm{N}_{2} \mathrm{O}$ emission and nitrogen loss [7, 8]. It is rather difficult to build a valid model for forecasting $\mathrm{TN}$ loss and $\mathrm{N}_{2} \mathrm{O}$ emission of the composting system based on traditional model. Neural network is a mathematical model that is inspired by the structure and functional aspects of biological neural networks, it provides a new approach for the nonlinear problems. Artificial neural networks (ANNs) have received great interest in various research fields include agriculture [9] and environment science [10]. BP neural network, which have a neural propensity for storing experimental knowledge, is a neural

\footnotetext{
* Corresponding author: baoli@cau.edu.cn
} 
network model that is most widely used in nonlinear forecast [11]. This paper presents a new method applying the technology of neural network to forecast the $\mathrm{N}_{2} \mathrm{O}$ emission and nitrogen loss during the swine manure composting. With this model, scientists and policy makers can use this model to set a reasonable parameter for composting program.

\section{The establishment of BP neural network model}

\subsection{Data extraction}

Data were extracted from peer-reviewed journal papers published until July 2018. Totally 68 valid data of $\mathrm{N}_{2} \mathrm{O}$ emission and nitrogen loss from 11 paper were included in this study. To minimize bias, all studies use swine manure and straw in composting. Detailed data are listed in table 1, giving the following information: proportion of $\mathrm{N}_{2} \mathrm{O}-\mathrm{N}$ emission on total nitrogen $(\%), \mathrm{TN}$ loss rate $(\%), \mathrm{C} / \mathrm{N}$ ratio, Moisture content $(\%)$, aeration rate $\left(\mathrm{L} / \mathrm{kg} \mathrm{min}^{-1}\right.$, dry matter), and superphosphate content (\%, dry matter).

Table 1. Data of nitrogen loss and $\mathrm{N}_{2} \mathrm{O}$ emission.

\begin{tabular}{|c|c|c|c|c|c|c|}
\hline $\mathrm{N}_{2} \mathrm{O}-\mathrm{N} / \mathrm{TN}$ & TN loss & $\begin{array}{c}\text { Moisture } \\
\text { content }\end{array}$ & $\mathrm{C} / \mathrm{N}$ & Aeration rate & SSP & Reference \\
\hline $0.68 \sim 1$ & $14.3 \sim 39.2$ & 67.6 & 15.4 & 0 & $0 \sim 13.2$ & {$[12]$} \\
\hline $0.04 \sim 0.65$ & $24 \sim 50.8$ & $55 \sim 65$ & $15 \sim 21$ & $0.12 \sim 0.36$ & 10 & {$[13]$} \\
\hline $1.5 \sim 7.3$ & $18.4 \sim 45.9$ & $65 \sim 75$ & $15 \sim 21$ & $0.24 \sim 0.72$ & 0 & {$[14]$} \\
\hline 0.73 & 33.01 & 70 & 20 & 0.38 & 0 & {$[15]$} \\
\hline 1.37 & 13.6 & 65 & 22.5 & 0 & 0 & {$[16]$} \\
\hline 1.5 & 43.9 & 52.2 & 25 & 0.25 & 0 & {$[17]$} \\
\hline $0.24 \sim 0.55$ & $25.44 \sim 42.34$ & 60 & $15 \sim 30$ & 0.24 & 0 & {$[18]$} \\
\hline $0.15 \sim 0.35$ & $30.50 \sim 42.34$ & 70 & $15 \sim 30$ & 0.5 & 0 & {$[19]$} \\
\hline $0.03 \sim 0.24$ & $29.5 \sim 45.2$ & $55 \sim 65$ & $15 \sim 21$ & $0.12 \sim 0.36$ & $0 \sim 24$ & {$[20]$} \\
\hline $1.58 \sim 6.69$ & $18.45 \sim 54.54$ & $63.4 \sim 75$ & $15 \sim 21$ & $0 \sim 0.72$ & 0 & {$[21]$} \\
\hline $0.5 \sim 4.36$ & $19.9 \sim 44.13$ & $63.7 \sim 70$ & $17.3 \sim 18.4$ & $0 \sim 0.54$ & 0 & {$[22]$} \\
\hline
\end{tabular}

\subsection{Set the parameter of neural network model}

In this study, we use three-layered neural network to establish forecasting model. Existing theory confirmed that arbitrary continuous functions could be approximated by threelayered neural network with feed forward structure [23]. The input variables of neural network model of nitrogen loss and $\mathrm{N}_{2} \mathrm{O}$ emissions are $\mathrm{C} / \mathrm{N}$, moisture content, aeration rate and superphosphate content, so the number of input neurons is 3; the output parameters are the proportion of $\mathrm{N}_{2} \mathrm{O}-\mathrm{N}$ emission in total nitrogen $\left(\mathrm{N}_{2} \mathrm{O}-\mathrm{N}\right)$ and the proportion total nitrogen loss ( $\mathrm{TN}$ loss), so the number of output neurons in the output layer is 2.The principle of forecast of neural network is described by a 4-N-2 ANN. That topology is shown in figure 1. 


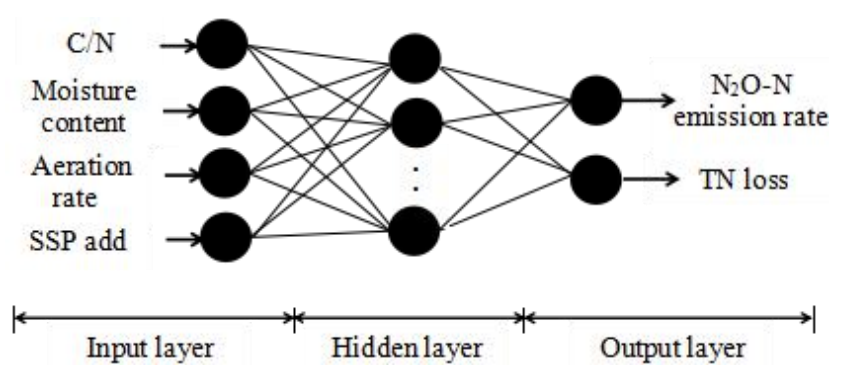

Fig. 1. The sketch map of BP network.

The neural network training program is processed under Matlab2016a. This paper used a fast training function Levenberg-Marquardt algorithm. This algorithm typically requires more memory but less time. Select 68 valid data, $70 \%$ of them (48 group) is used to training Neural Network, $15 \%$ is the share of testing data (10 group), the rest of them (10 group) is used to valid Neural Network. Other model parameters used in the BP neural network prediction model is shown in table 2.

Table 2. The BP neural network prediction model parameters.

\begin{tabular}{|c|c|}
\hline The parameter name & Value / Option \\
\hline Hidden layer nodes transfer function & tansig \\
\hline Output layer neuron excitation function & purelin \\
\hline Training function type & trainlm \\
\hline Max failure & 6 \\
\hline Max iteration number & 1000 \\
\hline The network learning rate & 0.001 \\
\hline Network training goal error & 0.00001 \\
\hline
\end{tabular}

\subsection{The number of neurons in the hidden layer}

The number of neurons in the hidden layer will affect the prediction precision of the model. Until now, it's still lack of theoretical basis to figure out the number of neurons in the hidden layer, researchers usually determined it empirically. In this paper, the numbojer of hidden layer nodes is initially set according to the below empirical formula:

$$
\mathrm{P}=\sqrt{m+n}+\alpha
$$

$\mathrm{P}$ is the number of the hidden layer nodes; $\mathrm{m}$ represents the number of input layer nodes; $n$ means the number of output nodes; $\alpha$ is a natural number between 1-10.

Under the MATLAB software platform and according to the training process above, the BP model was simulated and trained several times to find the number of hidden layers. Table 3 shows the prediction performance of BP neural network with changing of the hidden layer unit number. According to this Table, we found that when the hidden layer $\mathrm{N}=8$, the function is more feasible, so in this paper the number of ANN hidden layer is selected to be 8 .

Table 3. Prediction error under different hidden nodes of neural network.

\begin{tabular}{|c|c|c|c|c|c|}
\hline & $\mathrm{N}=4$ & $\mathrm{~N}=6$ & $\mathrm{~N}=8$ & $\mathrm{~N}=10$ & $\mathrm{~N}=12$ \\
\hline $\mathrm{MSE}$ & 20.3570 & 14.6735 & 12.9411 & 13.2661 & 15.5303 \\
\hline $\mathrm{R}$ & 0.6955 & 0.7849 & 0.8336 & 0.8037 & 0.7406 \\
\hline
\end{tabular}

\subsubsection{Error evaluation}


In order to evaluate the obtained results, the mean absolute percentage error (MAPE) and mean squared error (MSE) are used, which is given in the below formula (2), (3). The error index provides information on the short-term performance and represents a measure of the variation of predicted values around the measured data.

$$
\begin{aligned}
\text { MAPE } & =\frac{1}{n} \sum_{i=1}^{n}\left|\frac{y_{i}-\widehat{y_{i}}}{y_{i}}\right| \times 100 \% \\
\text { MSE } & =\frac{1}{n} \sum_{i=1}^{n}\left(y_{i}-\widehat{y}_{i}\right)^{2}
\end{aligned}
$$

where $y_{i}$ is the measured value of power out of the system; $\widehat{y_{i}}$ is the forecasting value of the power output; $\mathrm{n}$ represents the number of model forecasting samples. Different simulations have been performed in order to compare errors. And the error analysis is used to select the optimal number of hidden nodes.

\section{Simulation and analysis}

\subsection{Regression value}

The BP model synchronously predicts the training sample, validation sample, testing sample, and all samples while training by the regression equation. Figure 2 shows the regression results. The abscissa represents the target value; the ordinate represents the output value of the BP model. Regression R value is the regression coefficient, it measure the correlation between outputs and targets. The closer Regression value to 1 , the better is the BP model and the higher is the prediction accuracy. In this paper training sample $\mathrm{R}=0.98588$; validation sample $\mathrm{R}=0.97489$; testing sample $\mathrm{R}=0.94657$, the total $\mathrm{R}=0.97728$. The regression results show prediction is feasible and reliable.
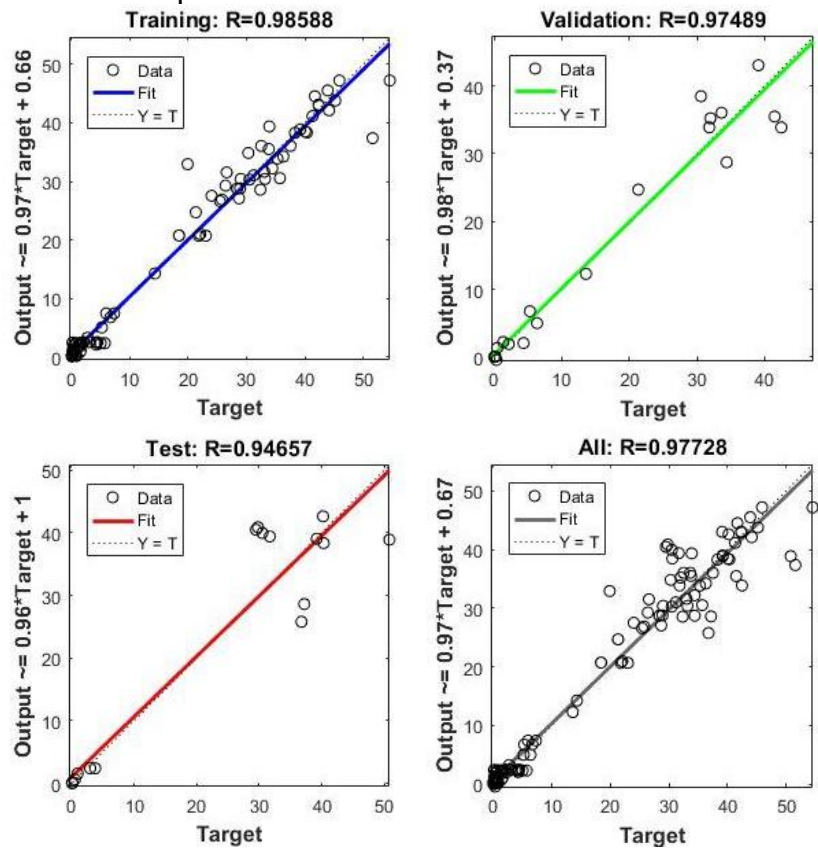

Fig. 2. Regression curve of model error.

\subsection{The mean squared error}


Mean Squared Error is the average squared difference between outputs and targets. Figure 3 shows the change of MSE during the process of net training, abscissa represents the number of iterations and the ordinate represents the mean squared error (MSE) between the model output value and the actual value. Mean square error (MSE) of the training sample becomes small gradually as iterative steps increase. Due to BP network's own restrictions, at the initial stage, the curve comes to faster convergence, at the latter it becomes more gently. When the forecasting model output value is close to actual value, the value of MSE is close to 0 . The MSE performance of train, validation and test is respectively shown in blue, green and red line. The dotted line shows that the validation results are the most ideal after the 15th iteration. This dotted line represents one of the set targets for the BP model to stop training.

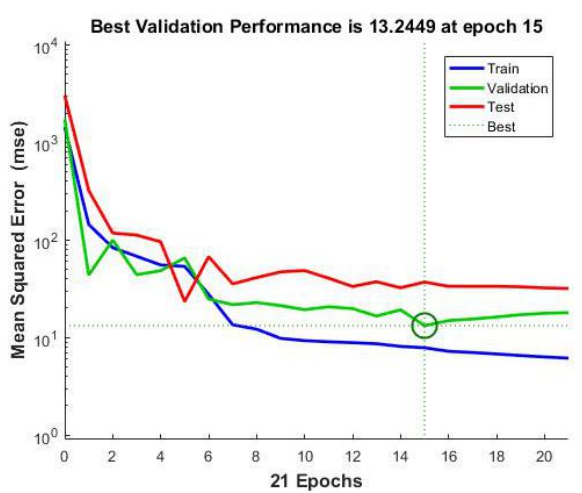

Fig. 3. Mean Squared Error of data in training process.

\subsection{BP Fitting result}

The predicted value and actual value of $\mathrm{N}_{2} \mathrm{O}-\mathrm{N}$ emissions and $\mathrm{TN}$ loss are shown in figure 4 and 5, respectively. Besides, we use traditional linear regression to forecast $\mathrm{N}_{2} \mathrm{O}-\mathrm{N}$ emissions and TN loss, the performance comparison is show in Table 4. It can be observed that in BP model, the predicted values are quite close to the actual. As for TN loss rate, the mean squared error (MSE) of Neural Network is 24.72, the mean absolute percentage error (MAPE) between the predicted and actual values arrived at $11.06 \%$. Better than linear regression, which the mean squared error (MSE) is 19.28 and the mean absolute percentage error (MAPE) $50.49 \%$. For $\mathrm{N}_{2} \mathrm{O}-\mathrm{N}$ emission predicts, the mean squared error (MSE) of Neural Network is 1.17, the mean absolute percentage error (MAPE) between the predicted and actual values arrived at $138.85 \%$. Better than linear regression, which the mean squared error (MSE) is 1.43 and the mean absolute percentage error (MAPE) 250.82\%.

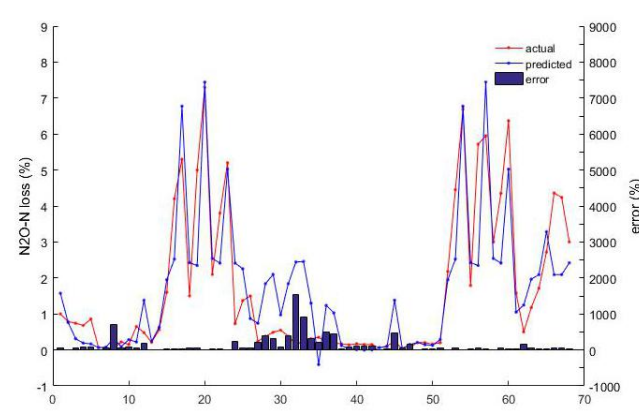

Fig. 4. Compensation results of $\mathrm{N}_{2} \mathrm{O}-\mathrm{N}$ emission.

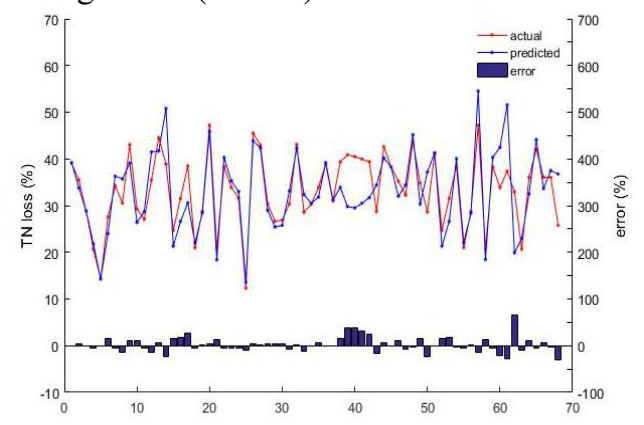

Fig. 5. Compensation results of TN loss. 
Table 4. The performance comparison between two prediction models.

\begin{tabular}{|c|c|c|c|}
\hline & Model & $\mathrm{N}_{2} \mathrm{O}-\mathrm{N}$ emission & TN loss \\
\hline \multirow{2}{*}{ MAPE (\%) } & BP network & 138.85 & 11.06 \\
\cline { 2 - 4 } & Linear regression & 250.82 & 19.28 \\
\hline \multirow{2}{*}{ MSE } & BP network & 1.17 & 24.72 \\
\cline { 2 - 4 } & Linear regression & 1.43 & 50.49 \\
\hline
\end{tabular}

\section{Conclusion}

Compare to traditional linear regression, the BP neural network prediction values have a good agreement with the experimental test values. The mean squared error (MSE) of nitrogen in BP model is 24.72; the mean absolute percentage error (MAPE) is $11.06 \%$, which is presented to explain the prediction is feasible and reliable. However, the mean absolute percentage errors of $\mathrm{N}_{2} \mathrm{O}$ emission arrive at $138.85 \%$, which is impermissible in the engineering application. In this study, the experimental data only involves 4 indexes, there is a further need more indexes such as initial $\mathrm{pH}$ and the volume of vessel, which also influence swine manure composting program. This will supplement and improve the accuracy of the neural network predicting $\mathrm{N}_{2} \mathrm{O}$ emission and nitrogen loss. Besides, more research is needed for other place or situation to enlarge the neural network.

\section{Acknowledgments}

This work was funded by Research on Key Technologies of Quantitative Evaluation of Non- $\mathrm{CO}_{2}$ Greenhouse Gas Emission Reduction in aquaculture Industry (2017YFF0211701).

\section{References}

1. Fukumoto, Y., Osada, T., Hanajima, D., \& Haga, K. (2003). Patterns and quantities of $\mathrm{NH}_{3}, \mathrm{~N}_{2} \mathrm{O}$ and $\mathrm{CH}_{4}$ emissions during swine manure composting without forced aeration--effect of compost pile scale. Bioresource Technology, 89(2), 109-114.

2. Szanto, G. L., Hamelers, H. V. M., Rulkens, W. H., \& Veeken, A. H. M. (2007). $\mathrm{NH}_{3}$, $\mathrm{N}_{2} \mathrm{O}$ and $\mathrm{CH}_{4}$, emissions during passively aerated composting of straw-rich pig manure. Bioresource Technology, 98(14), 2659-2670.

3. Morand, P., Peres, G., Robin, P., Yulipriyanto, H., \& Baron, S. (2005). Gaseous emissions from composting bark/manure mixtures. Compost Science \& Utilization, 13(1), 14-26.

4. Luo, Y., Li, G., Luo, W., Schuchardt, F., Jiang, T., \& Xu, D. (2013). Effect of phosphogypsum and dicyandiamide as additives on $\mathrm{NH}_{3}, \mathrm{~N}_{2} \mathrm{O}$ and $\mathrm{CH}_{4}$ emissions during composting. Acta Scientiae Circumstantiae, 25(7), 1338-1345.

5. Hao, X., Larney, F. J., Chang, C., Travis, G. R., Nichol, C. K., \& Bremer, E. (2005). The effect of phosphogypsum on greenhouse gas emissions during cattle manure composting. Journal of Environmental Quality, 34(3), 774-781.

6. Yang, F., Li, G., Shi, H., \& Wang, Y. (2015). Effects of phosphogypsum and superphosphate on compost maturity and gaseous emissions during kitchen waste composting. Waste Management, 36, 70-76.

7. Schuchardt, F. (2011). Effect of $\mathrm{C} / \mathrm{N}$ ratio, aeration rate and moisture content on ammonia and greenhouse gas emission during the composting. Journal of Environmental Sciences, 23(10), 1754-1760. 
8. Zhu, N. (2007). Effect of low initial $\mathrm{C} / \mathrm{N}$ ratio on aerobic composting of swine manure with rice straw. Bioresource Technology, 98(1), 9-13.

9. Topuz, A. (2010). Predicting moisture content of agricultural products using artificial neural networks. Advances in Engineering Software, 41(3), 464-470.

10. Nabavi-Pelesaraei, A., Rafiee, S., Hosseinzadeh-Bandbafha, H., \& Shamshirband, S. (2016). Modeling energy consumption and greenhouse gas emissions for kiwifruit production using artificial neural networks. Journal of Cleaner Production, 133, 924931.

11. Tan, W. H., Ooi, K. B., Leong, L. Y., \& Lin, B. (2014). Predicting the drivers of behavioral intention to use mobile learning: a hybrid sem-neural networks approach. Computers in Human Behavior, 36(C), 198-213.

12. Luo, Y., Li, G., Frank, S., Wang, K., Jiang, T., \& Luo, W. (2012). Effects of additive superphosphate on nh3, n2o and ch4 emissions during pig manure composting. Transactions of the Chinese Society of Agricultural Engineering, 28(22), 235-242.

13. Wu, J., He, S., Li, G., Li, Z., Bao, Y., \& Liang, Y. (2017). Process optimization of pollutant gases emission reduction with superphosphate addition during pig manure composting. Transactions of the Chinese Society for Agricultural Machinery.48(5), 304-311

14. Jiang, Frank, Schuchardt, Guoxue, Yuanqiu, \& Zhao. (2011). Effect of $\mathrm{c} / \mathrm{n}$ ratio, aeration rate and moisture content on ammonia and greenhouse gas emission during the composting. Journal of Environmental Sciences, 23(10), 1754-1760.

15. Li, D., Li, S., Li, G., \& Wang, K. (2016). Effects of additive on nitrogen loss during composting of pig manure and corn straw. Transactions of the Chinese Society of Agricultural Engineering. 32 (s2), 260-267.

16. Fu, X., Liu, Q., Li, L., Pan, et al. (2017). Effects of biochar on nitrogen transformation and greenhouse gas emissions during swine manure composting. Journal of AgroEnvironment Science. 36(9), 1893-1900.

17. Jiang, T., Ma, X., Tang, Q., Yang, J., Li, G., \& Schuchardt, F. (2016). Combined use of nitrification inhibitor and struvite crystallization to reduce the $\mathrm{NH}_{3}$ and $\mathrm{N}_{2} \mathrm{O}$ emissions during composting. Bioresource Technology, 217, 210-218.

18. Shen, Y. J. (2009). The Effect of Different Parameters on Gas Emission during Aerobic Composting. (Doctoral dissertation, China Agricultural University).

19. Ren, L. M. (2009). Study on Mechanism of Carbon and Nitrogen Loss and Control during Composting (Doctoral dissertation, China Agricultural University).

20. He, S. Z. (2016). The investigation of adding proportion of Superphosphate and control condition during composting based on the reduction of $\mathrm{CO}_{2}$ (Doctoral dissertation, China Agricultural University).

21. Zhao, Y.Q. (2010). The study on gases nitrogen emission rules during aerobic composting (Doctoral dissertation, China Agricultural University).

22. Jiang, T. (2011). The Greenhouse Gas Formation Mechanism During Composting and Mitigation Technologies Research (Doctoral dissertation, China Agricultural University).

23. Derks, E. P. P. A., Pastor, M. S. S., \& Buydens, L. M. C. (1995). Robustness analysis of radial base function and multi-layered feed-forward neural network models. Chemometrics \& Intelligent Laboratory Systems, 28(1), 49-60. 